\title{
Assessment of a probabilistic framework for combining structure- and ligand-based virtual screening
}

\author{
Simone Fulle*, Stuart M Armstrong, Paul W Finn, Garrett M Morris \\ From 7th German Conference on Chemoinformatics: 25 CIC-Workshop \\ Goslar, Germany. 6-8 November 2011
}

A wide variety of structure- and ligand-based virtual screening approaches have been developed that aim at finding potential leads to initiate drug discovery efforts. Since each method has its strengths and weakness, combining the outcome of different structure- and ligandbased approaches can be expected to decrease the number of false positive predictions. However, a reliable fusion of information from different methods is challenging. This holds true in particular for new target structures, where target specific performance experiences are missing.

Here, we assess the performance of a probilistic framework approach [1] that combines structure- and ligandbased information in a meaningful way by assigning probabilities that any two molecules are active. The approach is validated using two popular docking methods (GOLD and AutoDock) and an in-house ligand-based screening approach (ElectroShape [2]). Results of similarity search and docking calculations for the Directory of Useful Decoys (DUD) [3] are combined through rank fusion as well as a probabilistic framework approach.

The study will be used to answer questions such as: How far do the virtual screening-approaches used provide complementary or redundant hit lists? Does the fusion of structure- and ligand-based approaches consistently outperform any single screening metric? Using a probabilistic framework approach, is it possible to obtain a quantification of the confidence that any molecule will be active?

Published: 1 May 2012

\footnotetext{
* Correspondence: simone.fulle@inhibox.com
} InhibOx, Limited, Oxford, UK

C 2012 Fulle et al; licensee BioMed Central Ltd. This is an Open Access article distributed under the terms of the Creative Commons Attribution License (http://creativecommons.org/licenses/by/2.0), which permits unrestricted use, distribution, and reproduction in any medium, provided the original work is properly cited.

References

1. Swann S, Brown S, Muchmore S, Patel H, Merta P, Locklear J, Hajduk P: A unified, probabilistic framework for structure- and ligand-based virtual. J Med Chem 2011, 54:1223-1232.

2. Armstrong MS, Finn PW, Morris GM, Richards WG: Improving the accuracy of ultrafast ligand-based screening: incorporating lipophilicity into ElectroShape as an extra dimension. J Comput Aided Mol Des 2011, 25:785-790, doi:10.1007/s10822-011-9463-8.

3. Huang N, Shoichet BK, Irwin JJ: Benchmarking sets for molecular docking. J Med Chem 2006, 49:6789-6801.

doi:10.1186/1758-2946-4-S1-P7

Cite this article as: Fulle et al:: Assessment of a probabilistic framework

for combining structure- and ligand-based virtual screening. Journal of Cheminformatics 2012 4(Suppl 1):P7.
Publish with ChemistryCentral and every scientist can read your work free of charge

"Open access provides opportunities to our colleagues in other parts of the globe, by allowing anyone to view the content free of charge."

W. Jeffery Hurst, The Hershey Company.

- available free of charge to the entire scientific community

- peer reviewed and published immediately upon acceptance

- cited in PubMed and archived on PubMed Central

- yours - you keep the copyright

Submit your manuscript here:

http://www.chemistrycentral.com/manuscript/

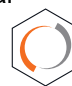

Chemistry Central 